\title{
The Endogenous Opioids Related with Antinociceptive Effects Induced by Electrical Stimulation into the Amygdala
}

\author{
Takami Nakamura ${ }^{1,2, *}$, Mihoko Tomida ${ }^{2}$, Toshiharu Yamamoto ${ }^{3}$, Hiroshi Ando ${ }^{2}$, Tetsuya \\ Takamata $^{1}$, Eiji Kondo ${ }^{4}$, Ikufumi Kurasawa ${ }^{5}$ and Naokazu Asanuma ${ }^{2}$ \\ ${ }^{I}$ Department of Oral and Maxillofacial Biology, Graduate School of Oral Medicine, Matsumoto Dental University, Japan \\ ${ }^{2}$ Department of Oral Physiology, Matsumoto Dental University, Japan \\ ${ }^{3}$ Department of Human Biology, Kanagawa Dental College, Japan \\ ${ }^{4}$ Department of Oral Anatomy, Matsumoto Dental University, Japan \\ ${ }^{5}$ Department of Prosthetic Dentistry, Matsumoto Dental University, Japan
}

\begin{abstract}
Pain relief is necessary and essential for dental treatments. Recently, the relationships of pain and emotion were studied, and electrical stimulation applied to the amygdala depressed the nociceptive response in the anterior cingulate cortex (ACC). Thus, the antinociceptive effects of the amygdala are elucidated, but its mechanism is not yet clarified. The present study was performed to investigate whether endogenous opioid system is related to the depression, and the quantitative changes of endogenous opioids induced by electrical stimulation to the amygdala. We investigated immunohistologically c-Fos expression to confirm the activated neurons, as well as the distribution and the amount of endogenous opioids ( $\beta$-endorphin, enkephalin and dynorphin $A$ ) in the brain using male Wistar rats, when electrical stimulation was applied to the central nucleus of the amygdala $(\mathrm{CeA})$ or noxious stimulation was delivered to the peripheral tissue. c-Fos expression in the ipsilateral ACC was increased by electrical stimulation to the CeA. However, only a small amount of endogenous opioids was observed in the ACC when noxious stimulation or electrical stimulation was applied. In contrast, the amount of dynorphin $\mathrm{A}$ in the periaqueductal gray (PAG) was increased by electrical stimulation to the CeA, and the amount of $\beta$-endorphin in the PAG was increased by noxious stimulation to the peripheral tissue. The results suggest that dynorphin $\mathrm{A}$ in the PAG induced by electrical stimulation to the CeA activate the descending antinociceptive system, and suggest that the nociceptive response in the ACC is depressed indirectly.
\end{abstract}

Keywords: Amygdala, anterior cingulate cortex, $\beta$-endorphin, enkephalin, dynorphin A, periaqueductal gray.

\section{INTRODUCTION}

Some patients may suffer from acute pain from the teeth during a visit to the dental clinic. The sense such as acute pain sometimes may induce their stress and anxiety. Therefore first we should treat to reduce their pain. There are mainly two kinds of ascending pathways for pain perception, sensory discriminative pathway involving sensory cortex and emotion cognitive pathway involving anterior cingulate cortex (ACC), insular cortex (INS) and amygdala, and there is an endogenous descending antinociceptive system composing from Periaqueductal Gray(PAG)-rostral ventromedial medulla-spinal cord [1]. Recently, it is reported that the ACC, INS and amygdala play important roles in emotional responses and are considered to be a critical component of the pain matrix [1-4]. The previous study has confirmed that brief electrical stimulation applied to the medial or central nucleus of the amygdala (MeA or CeA) evokes antinociception in the rat and cat [5-7]. Similarly, electrical stimulation

*Address correspondence to this author at the Department of Oral Physiology, Matsumoto Dental University, 1780 Hirooka-Gobara, Shiojiri, 3990781 Japan; Tel/Fax:+81-263-51-2053; E-mail: takami@po.mdu.ac.jp to the amygdala results in increased thresholds for pain related behavior [8]. Thus, nu merous studies have demonstrated that the amygdala is involved in antinociception, but its mechanism has not yet been clarified entirely.

According to the electrophysiological analysis, mechanical noxious stimulation applied to peripheral tissue evoked nociceptive discharges in the prefrontal cortex including the ACC $[9,10]$, and these nociceptive responses were inhibited by high frequency of electrical stimulation $(100 \mathrm{~Hz}+20 \mu \mathrm{A}$ for $30 \mathrm{~s}$ ) delivered to the basolateral nucleus of the amygdala (BLA) [9]. On the other hand, previous study using fMRI demonstrated that a negative blood oxygen level dependentsignal within the pregenual ACC induced by painful thermal stimulation was abolished by naloxone, suggesting that endogenous opioids led to deactivation of the pregenual ACC [11].

Endogenous opioid peptides are classified into enkephalins bound to $\delta$-opioid receptors (DOR), endorphins bound to $\mu$-opioid receptors (MOR) and dynorphins bound to $\kappa$-opioid receptors (KOR). These receptors belong to the superfamily of $\mathrm{G}$ protein-coupled receptors $[12,13]$. DOR expresses in the amygdala while exhibiting limited binding 


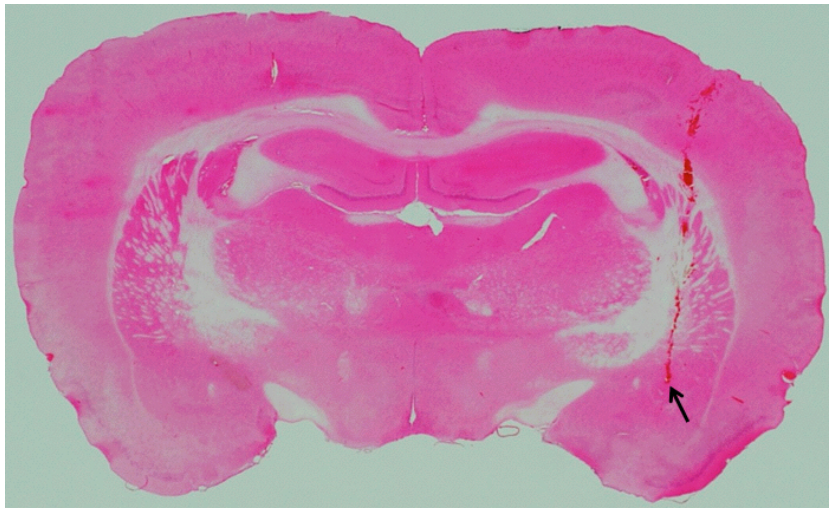

Fig. (1). Location of an electrode-inserted site in the CeA. The photograph shows an example of location of an electrodeinserted site in the CeA. The stimulated area was confirmed by staining with hematoxylin-eosin. Arrow shows the stimulated point.

in the thalamus and hypothalamus, MOR expresses in the thalamus, hippocampus, amygdala and brainstem, and KOR expresses in the hypothalamus, amygdala and brainstem [1417]. These opioids play an important role of providing efficient analgesics to inhibit neural excitability or neuronal firing rate; they also have the effects of euphoria and inhibition of fear in the human $[17,18]$.

It is thought that endogenous opioids increase in the brain including brainstem when electrical stimulation is applied to the amygdala, which depresses neural discharge in the ACC. However, the distribution and the quantitative change of endogenous opioids secreted in the brain after electrical stimulation at the amygdala have been scarcely investigated immunohistologically. We investigated the distribution and quantitative change of the endogenous opioids in the ACC, amygdala, PAG and nucleus raphe magnus (NRM) after electrical stimulation into the $\mathrm{CeA}$ or the noxious stimulation into the peripheral tissue. Simultaneously, we investigated cFos expression to identify neurons activated by noxious or electrical stimulation. And the endogenous opioidergic effects related with the nociceptive response in the ACC depressed by electrical stimulation into the amygdala were discussed.

\section{MATERIALS AND METHODS}

\section{Animal Subjects}

Male Wistar rats (250-320g) provided by Japan SLC, Inc. were used for this study. Animal treatments were performed with permission from the Experimental Animal Committee of Matsumoto Dental University, employing guidelines established by the committee. All efforts were made to minimize the number of animals used and the distress to the animals.

Four groups of the rats were prepared for this study; group 1: control $(n=5)$, group 2: formalin-injected to the right hind paw $(n=5)$, group 3: electrically stimulated to the CeA $(n=5)$, group 4: sham-operated $(n=5)$.

\section{Formalin Microinjection}

The animal was moved to the laboratory from the breeding room. As noxious stimulation, $0.1 \mathrm{ml}$ of formalin solution, i.e. $0.1 \mathrm{M}$ phosphate buffer ( $\mathrm{PB}, \mathrm{pH}$ 6.9) containing 4\% paraformaldehyde, was injected subcutaneously into the right hind paw. After formalin injection, the animal was placed in a clear plastic box for 60 minutes, and nociceptive behavior such as lifting and licking of the paw was checked to confirm the effect of noxious stimulation. After $60 \mathrm{~min}-$ utes, the animal was anesthetized with the pentobarbital sodium $(60 \mathrm{mg} / \mathrm{kg}$, i.p.) and perfused through the heart with $0.9 \% \mathrm{NaCl}$ followed by $4 \%$ paraformaldehyde containing $0.2 \%$ picric acid in $0.1 \mathrm{M} \mathrm{PB}(\mathrm{pH} 6.9)$. The brain, including the brainstem, was rapidly dissected out and further fixed for 1 day at $4^{\circ} \mathrm{C}$ in the same fixative. Untreated animals were used as controls.

\section{Electrical Stimulation Applied to the Amygdala}

The animal was anesthetized with pentobarbital sodium (75-100 $\mathrm{mg} / \mathrm{kg}$, i.p.). The head was immobilized in a stereotaxic equipment. The skull was exposed and a small hole was drilled with a dental bar above the amygdala (coordinates: $2.5-4.0 \mathrm{~mm}$ posterior and 4.5-5.0 $\mathrm{mm}$ lateral to the bregma, $6.5-7.5 \mathrm{~mm}$ deep from the cortical surface) following the atlas of Paxinos and Watson (2005). A screw was arbitrarily placed in the adjacent bone for the grounding. A stainless-steel electrode (EKB-9003, 0.3 $\times 90 \mathrm{~mm}$, Nihon Bioresearch Inc., Japan) was inserted into the amygdala using One-axis Motorized Stereotaxic Micromanipulator (with Digital Scale) (DMA-1511, Narishige, Japan), and electrical stimulation $(2 \mu \mathrm{A}, 100 \mathrm{~Hz})$ was applied for 15 seconds. After 60 minutes, electrical stimulation $(100 \mu \mathrm{A}$, direct current) was applied again for 20 seconds to mark a part stimulated, and then the electrode was removed. The animal was released from the stereotaxic equipment and was perfusionfixed as in the formalin injection experiment. Sham-operated rats were inserted the electrode into the amygdala without applying electrical stimulation.

\section{Histology and Immunohistochemistry}

After fixation (the same procedure as in the formalin injection experiment), the brain was washed in $0.1 \mathrm{M}$ phosphate-buffered saline (PBS, $\mathrm{pH} 7.4$ ) and immersed in $20 \%$ sucrose in $0.1 \mathrm{M} \mathrm{PBS}\left(\mathrm{pH} \mathrm{7.4)}\right.$ for 2 days at $4^{\circ} \mathrm{C}$. The sample was cut into $20 \mu \mathrm{m}$-thick transverse sections using a cryostat (Leica, Germany). Some sections were stained with hematoxylin-eosin to confirm the stimulated area (Fig. 1). The other sections were collected in 0.1 M PBS ( $\mathrm{pH} 7.4$ ) containing $0.02 \%$ sodium azide, and immunostained by the freefloating method after more than 1 week.

The distribution of following opioids, as well as c-Fos, was examined using the antibodies shown in the parentheses: $\beta$-endorphin (rabbit anti- $\beta$-endorphin polyclonal antibody, Millipore, Temecula, CA), enkephalin (rabbit leucine enkephalin polyclonal antibody, Immunostar, Hudson, WI), dynorphin A (rabbit dynorphin A polyclonal antibody, Phoenix Pharmaceuticals, Inc., Burlingame, CA), and c-Fos (rabbit anti-c-Fos [Ab-5] [4-17] polyclonal antibody, Millipore, Temecula, CA).

After washing 2 days at room temperature in $0.1 \mathrm{M}$ PBS containing $0.3 \%$ Triton $\mathrm{X}-100$, the sections were treated with $1 \% \mathrm{H}_{2} \mathrm{O}_{2}$ in $0.1 \mathrm{M}$ PBS (pH 7.4), and washed in 0.1 M PBS $(\mathrm{pH} 7.4)$ at room temperature. The sections were incubated with the primary antibodies ( $\beta$-endorphin, 1: 500; enkephalin, 1: 1,000; dynorphin A, 1: 500; c-Fos, 1: 2,500) 


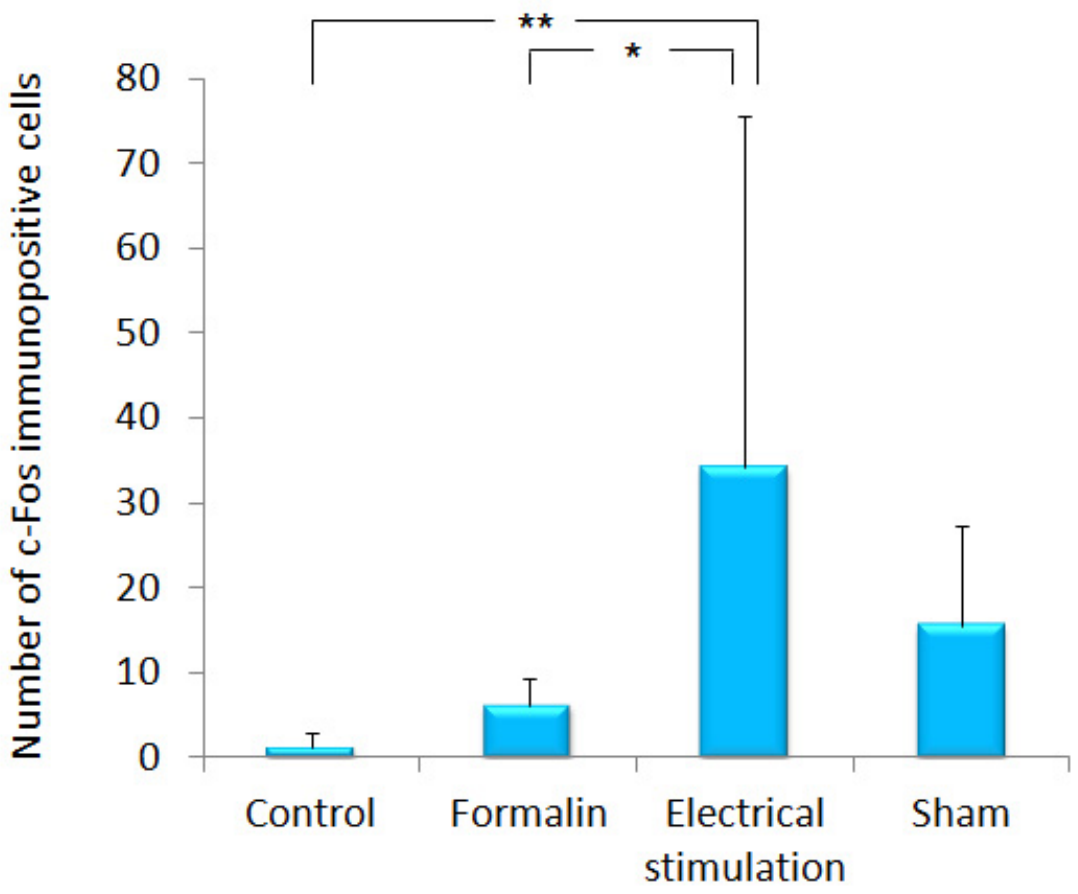

Fig. (2). The number of c-Fos immunopositive cells in the ipsilateral ACC.

The graph shows the number of c-Fos immunopositive cells in the ipsilateral ACC. Data represent mean \pm S.D. of 5 rats per treatment. $* \mathrm{p}<0.05, * * \mathrm{p}<0.001$.

diluted with 0.1 M PBS ( $\mathrm{pH} 7.4$ ) containing $1 \%$ bovine serum albumin (BSA) and $0.3 \%$ Triton X-100 for 2 days at $4{ }^{\circ} \mathrm{C}$. After washing in $0.1 \mathrm{M}$ PBS containing $0.3 \%$ Triton X100 for 1 hour at room temperature, the sections were incubated with the secondary antibody (biotinylated anti-rabbit IgG $[\mathrm{H}+\mathrm{L}]$ affinity purified, Vector Laboratories, Inc., Burlingame, CA) diluted to 1: 200 with $0.1 \mathrm{M}$ PBS containing BSA and $0.3 \%$ Triton $\mathrm{X}-100$ for 90 minutes at room temperature. After washing again in PBS containing $0.3 \%$ Triton X-100, the sections were incubated with the tertiary antibody (VECTASTAIN ABC kit, Vector Labolatories, Inc., Burlingame, CA) diluted to 1: 100 with PBS containing $0.3 \%$ Triton $\mathrm{X}-100$ for 30 minutes at room temperature, and then washed in PBS containing $0.3 \%$ Triton X-100 for 30 minutes, followed by further washing with $0.05 \mathrm{M}$ Tris- $\mathrm{HCl}$ buffer ( $\mathrm{pH}$ 7.4) for 30 minutes at room temperature. The sections were reacted with diaminobenzidine hydrochloride in $0.05 \mathrm{M}$ Tris- $\mathrm{HCl}$ buffer containing $0.005 \%$ hydrogen peroxide for 5 minutes at room temperature, and washed in 0.05 $\mathrm{M}$ Tris-HCl buffer ( $\mathrm{pH}$ 7.4) for 10 minutes at room temperature. The sections were mounted on MAS-corted glass slides, dried at least for 1 day, and then coverslipped.

\section{Counting and Statistical Analysis}

Immunostained sections were photographed by a digital camera (Olympus Corp., Japan). The photographs were converted to monochrome, and immunopositive amount in a square of $400 \mu \mathrm{m}$ (c-Fos) or $100 \mu \mathrm{m}$ (endogenous opioids) in the same areas of the brain (amygdala, ACC, caudate putamen, INS, habenular nucleus, paraventricular thalamic nucleus, PAG and NRM) per section was determined by using an appropriate software (Adobe Photoshop CS3 Extended, Adobe Systems Inc., U.S.A.). As regard the PAG, four regions, i.e. dorsomedial, right and left lateral and ventrolateral PAG, were determined. All data were expressed as mean \pm standard deviation $\left(\mu \mathrm{m}^{2}\right)$. Kruskal-Wallis test was applied to examine whether there were any differences among the four groups, and if the difference turned out to be significant, Sheffé's F test was carried out to clarify among which groups the significant differences existed.

\section{RESULTS}

\section{c-Fos Expression}

In control rats (group 1), c-Fos immunopositive neurons were observed in the ACC, amygdala (particularly MeA), hypothalamus and paraventricular thalamic nucleus. When formalin was injected into the right hind paw (group 2), cFos expression was observed, in addition to the abovementioned regions, in the INS and PAG. In electrically stimulated rats (group 3), and sham-operated rats (group 4), c-Fos expression was observed, in addition to the regions of the group 1, in the INS, amygdala (particularly CeA and MeA), layer 2 cortex and PAG. The expression owing to noxious stimulation or electrical stimulation was observed in the bilateral $\mathrm{CeA}$ and $\mathrm{MeA}$ of the amygdala.

In the rats of the group 3 and 4, c-Fos expression was observed evidently in the ipsilateral ACC and INS as compared with the contralateral region to the stimulated side. As compared with the group $1(1.2 \pm 1.64)$, c-Fos expression in the ipsilateral ACC was increased significantly in the group 3 $(34.2 \pm 41.35, \mathrm{p}<0.001)$. As compared with the group 2 (6.2 \pm 3.21 ), c-Fos expression in the ipsilateral ACC was increased significantly in the group $3(\mathrm{p}<0.05)$. There was no difference in c-Fos expression in the ipsilateral ACC between the group 1 and 4 (Figs. 2 and 3 ). 

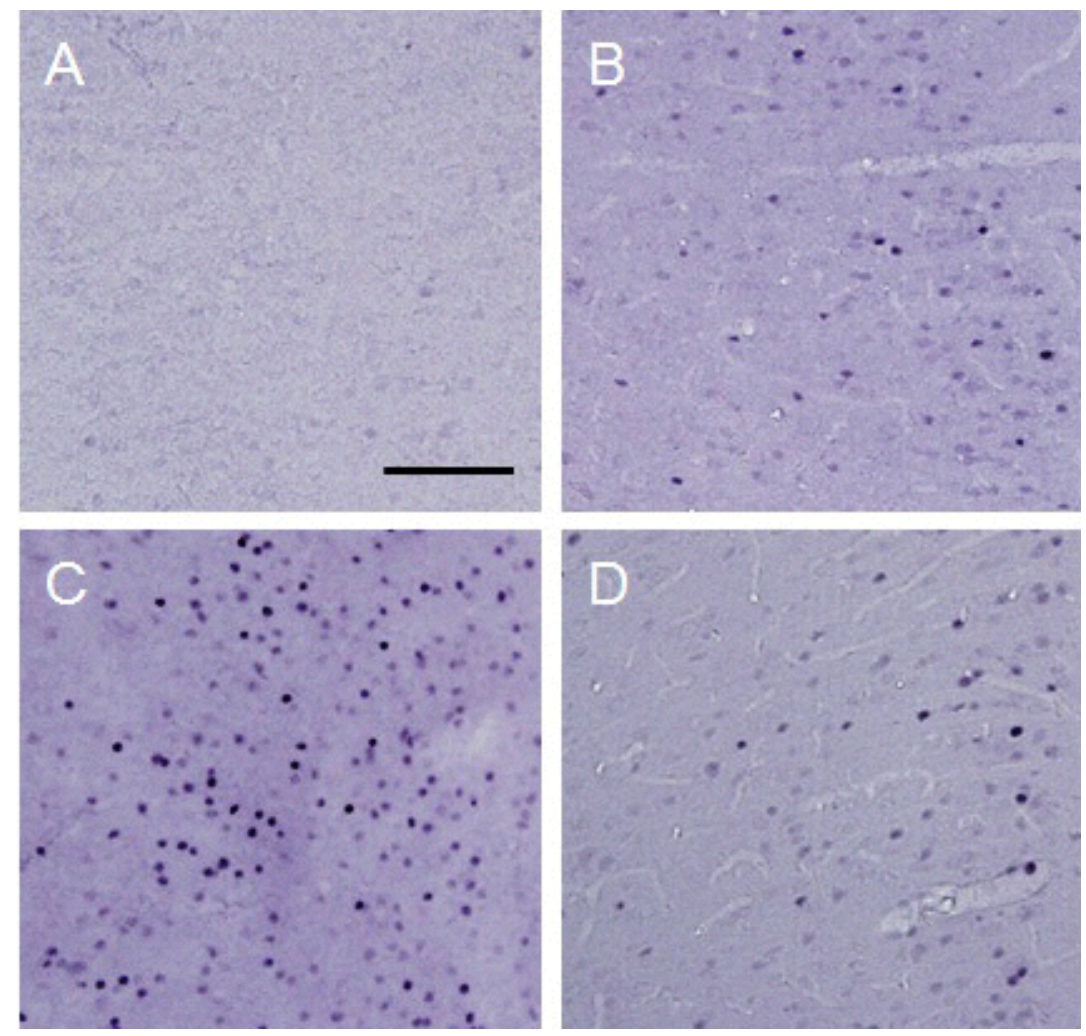

Fig. (3). c-Fos expression in the ipsilateral ACC.

Photographs show an example of c-Fos expression in the ipsilatereal ACC for each treatment. Each photograph represents a square of $400 \times$ $400 \mu \mathrm{m}$. A: control (group 1), B: formalin-injected (group 2), C: electrically stimulated to the CeA (group 3), D: sham-operated (group 4). Scale bar $=100 \mu \mathrm{m}$.

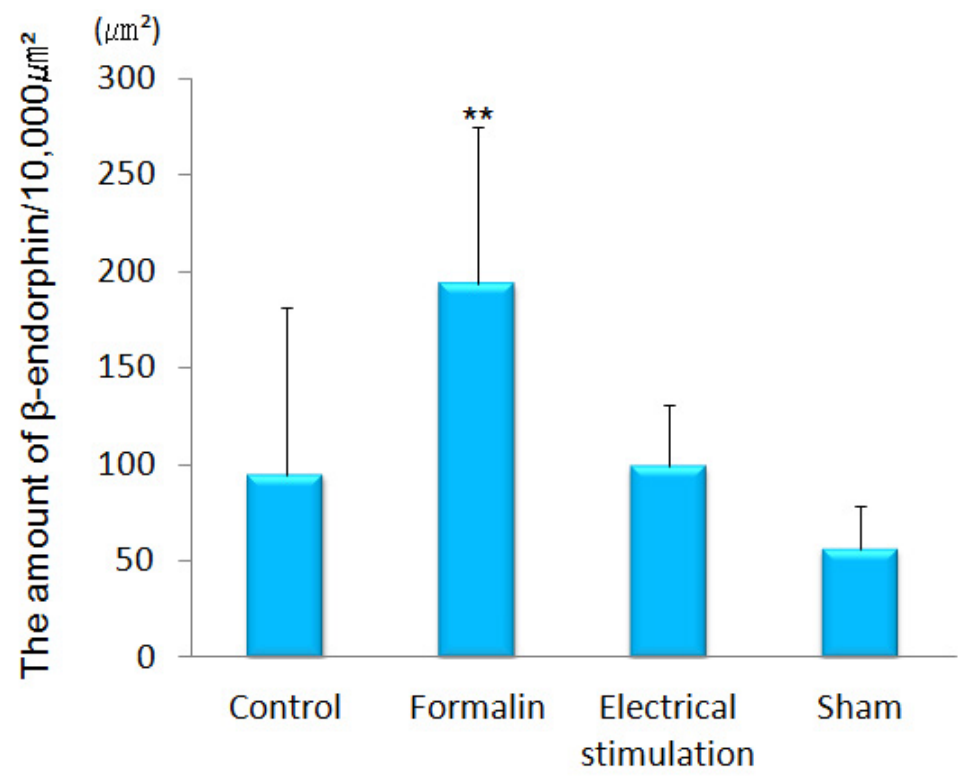

Fig. (4). The amount of $\beta$-endorphin in the lateral PAG.

The graph shows the amount of $\beta$-endorphin in the lateral PAG. $\beta$-endorphin was increased significantly in the lateral PAG of formalininjected rats as compared with the other groups. $(\mathrm{n}=5) * * \mathrm{p}<0.001$. 

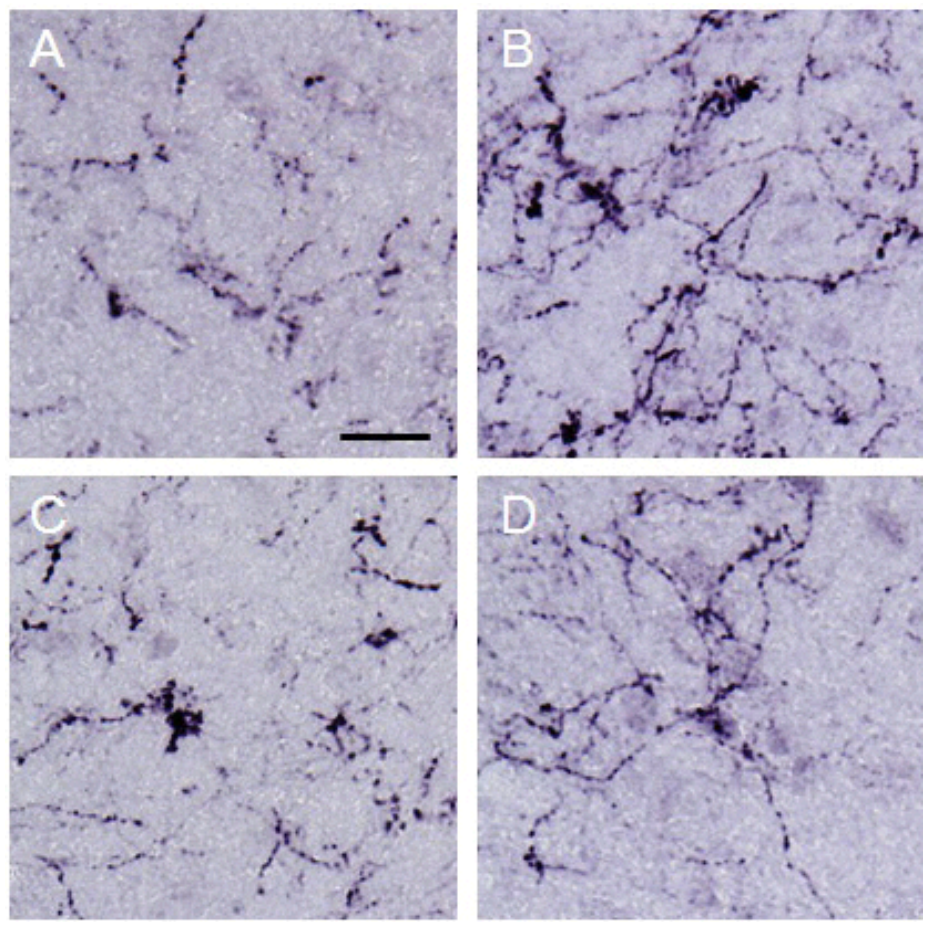

Fig. (5). $\beta$-endorphin observed in the lateral PAG.

Photographs show $\beta$-endorphin observed in the lateral PAG. Each photograph represents a square of $100 \times 100 \mu \mathrm{m}$. A: control (group 1), B: formalin-injected (group 2), C: electrically stimulated to the CeA (group 3), D: sham-operated (group 4). $\beta$-endorphin in the lateral PAG was increased by noxious stimulation applied to the right hind paw. Scale bar $=20 \mu \mathrm{m}$.

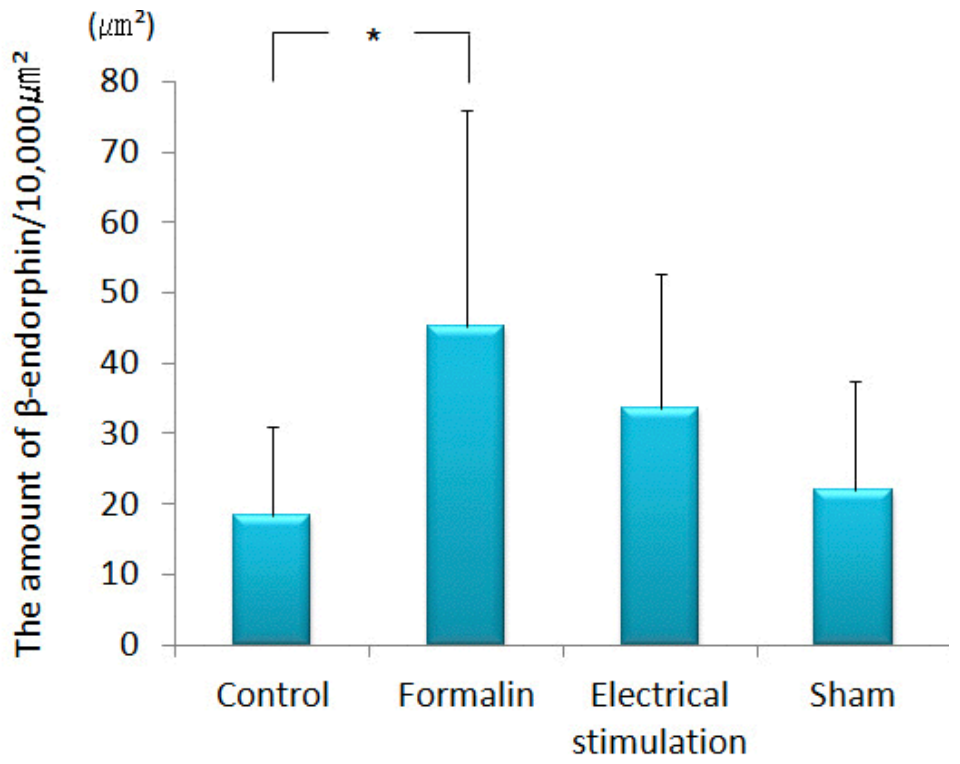

Fig. (6). The amount of $\beta$-endorphin observed in the MeA.

The graph shows the amount of $\beta$-endorphin observed in the MeA. $\beta$-endorphin was increased significantly in the MeA of formalin-injected rats as compared with the control. $(\mathrm{n}=5) * \mathrm{p}<0.05$.

\section{The Amount of $\beta$-endorphin}

$\beta$-endorphin immunopositive cell somata were observed in the arcuate nucleus. $\beta$-endorphin was conspicuous in the axons and terminals of the septal nucleus, paraventricular thalamic nucleus, hypothalamus (except for the ventromedial hypothalamic nucleus), amygdala (particularly $\mathrm{MeA}$ ) and PAG. In the ACC, only a few was observed. The amount of $\beta$-endorphin in the lateral PAG was increased significantly in the group $2\left(193.60 \pm 81.00 \mu \mathrm{m}^{2}\right)$ as compared with that in the group $1\left(94.64 \pm 86.58 \mu \mathrm{m}^{2}, \mathrm{p}<0.001\right)$, group $3(98.90 \pm$ $\left.31.73 \mu \mathrm{m}^{2}, \mathrm{P}<0.001\right)$ and group $4\left(56.12 \pm 22.31 \mu^{2}\right.$, $\mathrm{p}<0.001$ ) (Figs. 4 and 5). $\beta$-endorphin in the MeA was significantly increased in the group $2\left(45.35 \pm 30.64 \mu \mathrm{m}^{2}\right)$ compared with that in the group $1\left(18.31 \pm 12.66 \mu \mathrm{m}^{2}, \mathrm{p}<0.05\right)$. Compared with the group 4 , the amount of $\beta$-endorphin in the group 3 tended to increase in the MeA, although no significant difference was obtained (Figs. 6 and 7). 

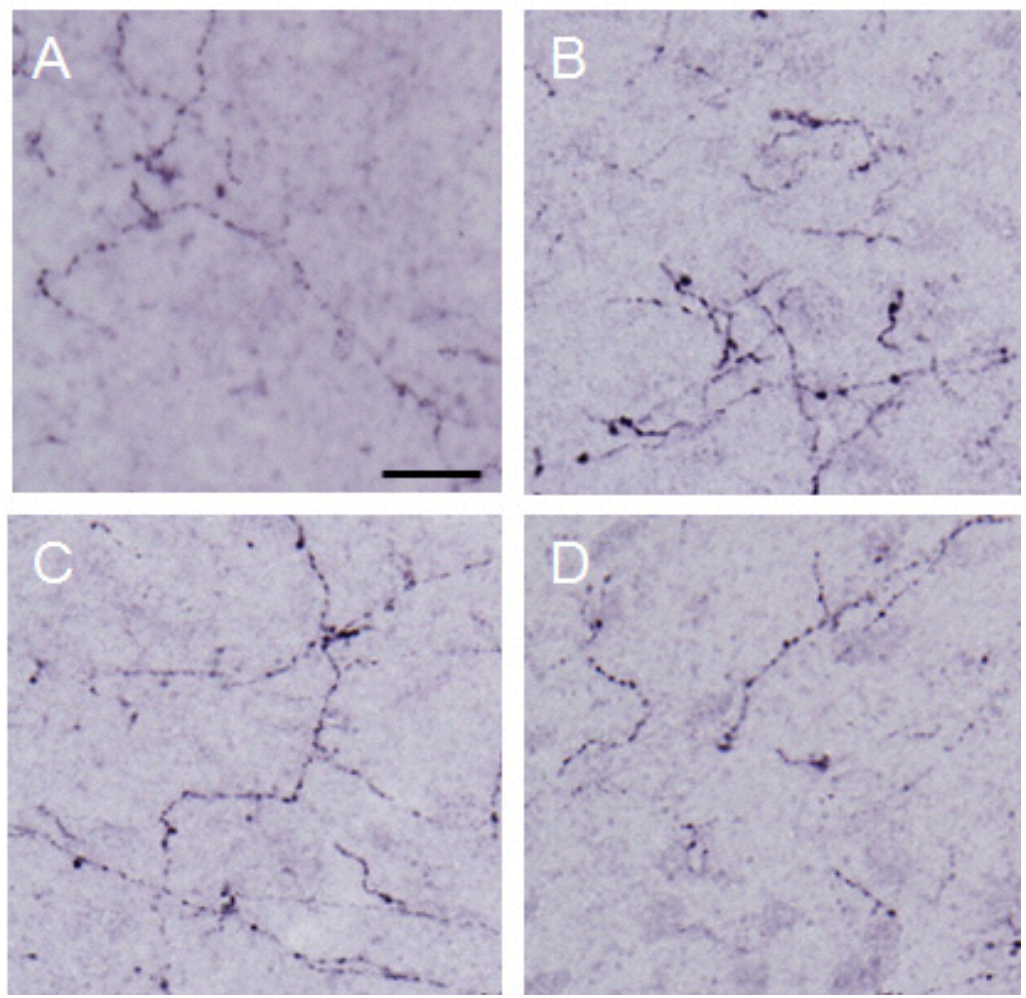

Fig. (7). $\beta$-endorphin in the MeA.

Photographs show $\beta$-endorphin in the MeA. Each photograph represent a square of $100 \times 100 \mu \mathrm{m}$. A: control (group 1), B: formalininjected (group 2), C: electrically stimulated to the CeA (group 3), D: sham-operated (group 4). Scale bar $=20 \mu \mathrm{m}$.

\section{The Amount of Enkephalin}

Enkephalin was observed in the paraventricular thalamic nucleus, hypothalamus, amygdala, PAG and NRM. Enkephalin immunopositive cell somata were observed in the CeA and hypothalamus. Small amounts of enkephalin were observed in the basolateral and lateral nuclei of the amygdala as compared with the other nuclei of the amygdala. In the ACC, only a few was observed. The amount of enkephalin observed in the lateral PAG and MeA have no significant difference among the four groups (data not shown).

\section{The Amount of Dynorphin A}

Dynorphin A was observed conspicuously in the paraventricular thalamic nucleus, hypothalamus, amygdala (particularly in the CeA), hippocampus, PAG and NRM. Immunopositive cell somata were observed in the $\mathrm{CeA}$ and arcuate nucleus. In the ACC, only a few was observed. Dynorphin A in the lateral PAG of the group 3 (148.10 \pm $96.80 \mu \mathrm{m}^{2}$ ) was significantly increased as compared with that in the group $1\left(61.64 \pm 39.19 \mu \mathrm{m}^{2}, \mathrm{p}<0.001\right)$ and group 4 $\left(53.35 \pm 37.97 \mu \mathrm{m}^{2}, \mathrm{p}<0.001\right)$. Dynorphin A of the group 2 $\left(115.22 \pm 57.14 \mu \mathrm{m}^{2}\right)$ was increased in the lateral PAG as compared with the group $4\left(53.35 \pm 37.97 \mu \mathrm{m}^{2}, \mathrm{p}<0.05\right)$ (Figs. 8 and 9). In the MeA, no difference was obtained among the four groups (data not shown).

\section{DISCUSSION}

The amygdala relates with emotional responses such as an emotional evaluation of sensory stimuli, emotional learn- ing and affective disorders including anxiety and depression [4]. Many studies have reported that the amygdala is also a major component of the descending pain-modulating pathway in the brain and plays an important role in regulating spinal nociceptive transmission $[8,19,20]$. One area of the amygdala, the $\mathrm{CeA}$ has been called the 'nociceptice amygdala' because of its high-content of neurons that respond to painful stimuli, and serves as a major output nucleus of the amygdala projecting to the brainstem $[4,5,21]$. Previous study indicated that a surprisingly large proportion of the neurons that project into major CeA out-pathway was directly inhibited through opioid receptors [22]. The CeA is a major amygdaloid contributor to morphine antinociception in the rat tail-flick and formalin pain assays [3]. Bilateral lesions of the CeA, but not BLA, reliably attenuate morphine-antinociception during the second phase of the formalin test without affecting the baseline-nociception [23]. Therefore we also performed electrical stimulation to the $\mathrm{CeA}$ of the amygdala.

In the present study, c-Fos expression was significantly increased in the ipsilateral ACC by electrical stimulation to the CeA compared with control or formalin injection (Fig. 2). The ACC is on the medial ascending pathway of pain from peripheral tissue, however, c-Fos expression did not increase by noxious stimulation to the peripheral tissue. Our results suggested that the neuron in the ACC would connect with that in the $\mathrm{CeA}$ of the amygdala directly or indirectly.

The mechanism of analgesia by opioids at the spinal and supraspinal levels has been clarified substantially and explained as follows: The opioid receptors are expressed in the 


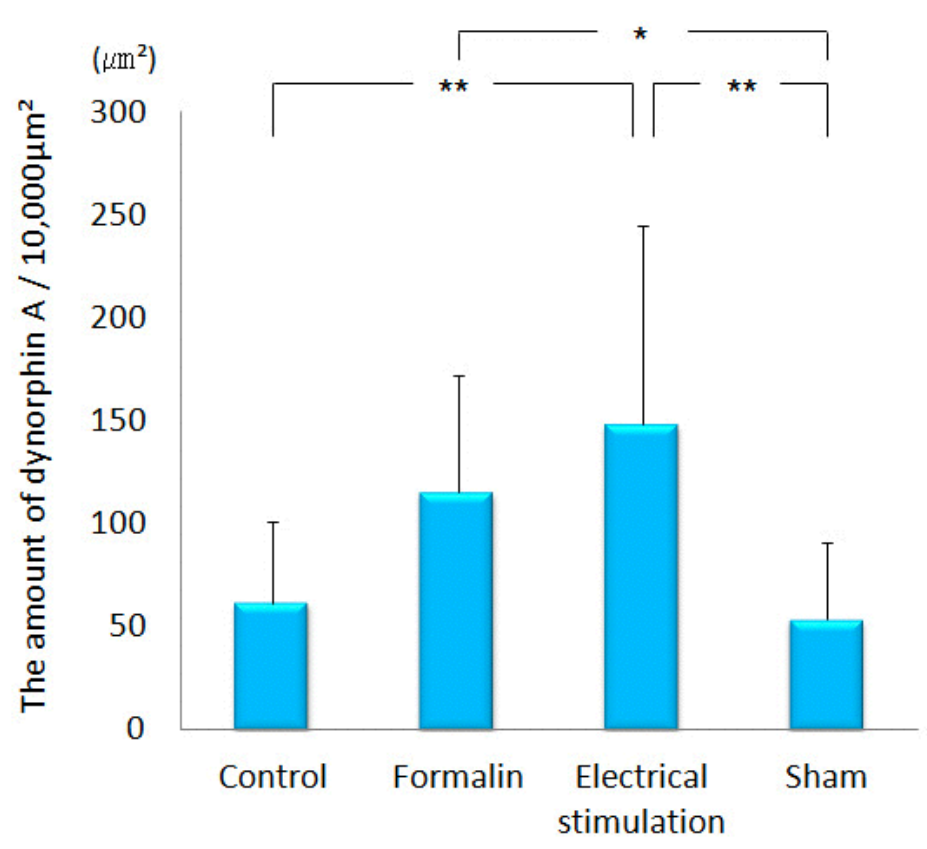

Fig. (8). The amount of dynorphin A observed in the lateral PAG.

The graph shows the amount of dynorphin A observed in the lateral PAG. Dynorphin A was increased significantly in the MeA by electrical stimulation applied to the CeA. ${ }^{*} \mathrm{p}<0.05, * * \mathrm{p}<0.001$.
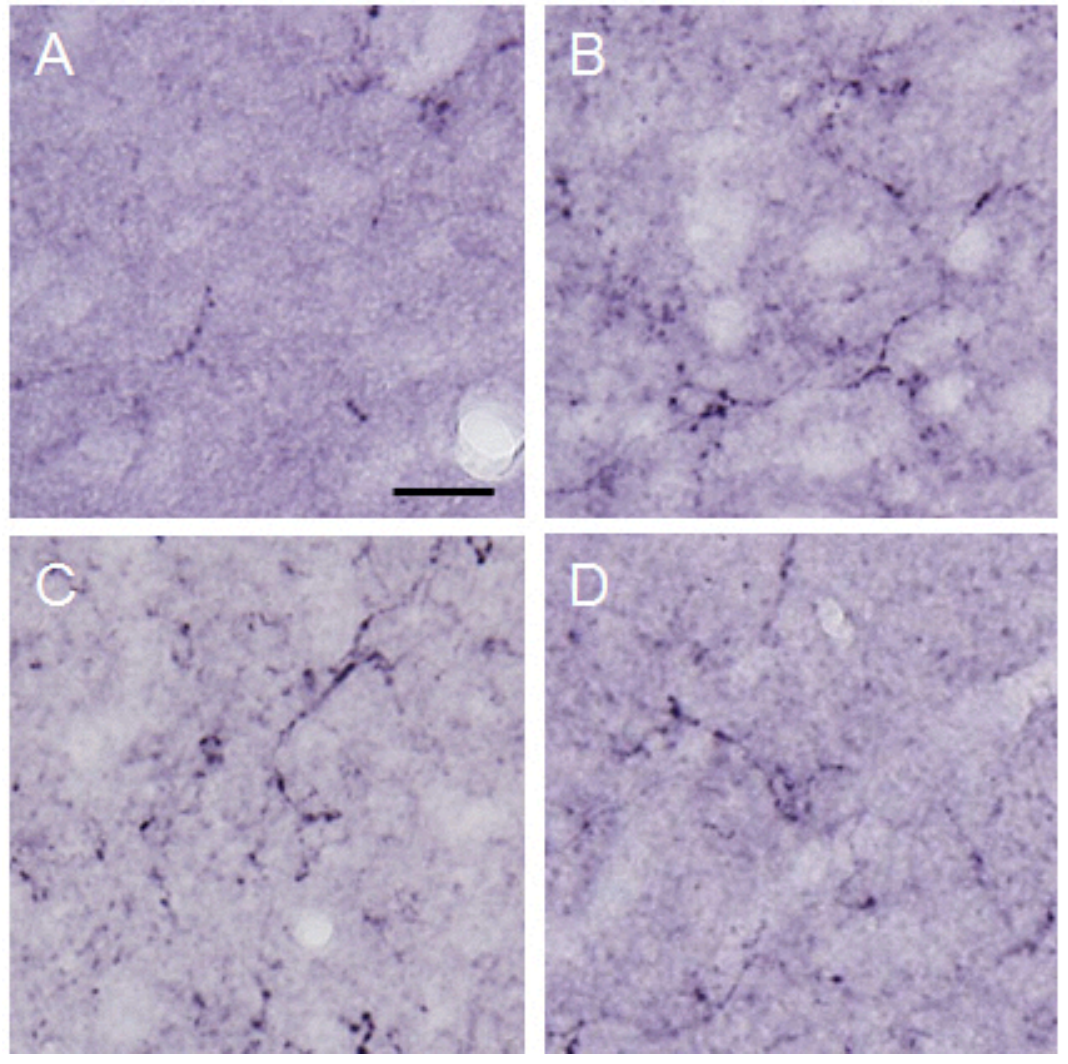

Fig. (9). Dynorphin A observed in the lateral PAG.

Photographs show dynorphin A observed in the lateral PAG. Each photograph represents a square of $100 \times 100 \mu \mathrm{m}$. A: control (group 1), B: formalin-injected (group 2), C: electrically stimulated to the CeA (group 3), D: sham-operated (group 4). Scale bar $=20 \mu \mathrm{m}$.

neurons such as (1) PAG output neurons, (2) ON cells, one of the two major population of rostral ventromedial medulla output neurons, whose activity coincide with spinal nociceptive reflex, and (3) GABA neurons, which relate to OFF cells whose activity is associated with suppression of nociceptive reflex. Activation of these opioid receptors induces inhibition of cAMP synthesis, closing of calcium channels and/or opening of potassium channels, and attenuates release of 


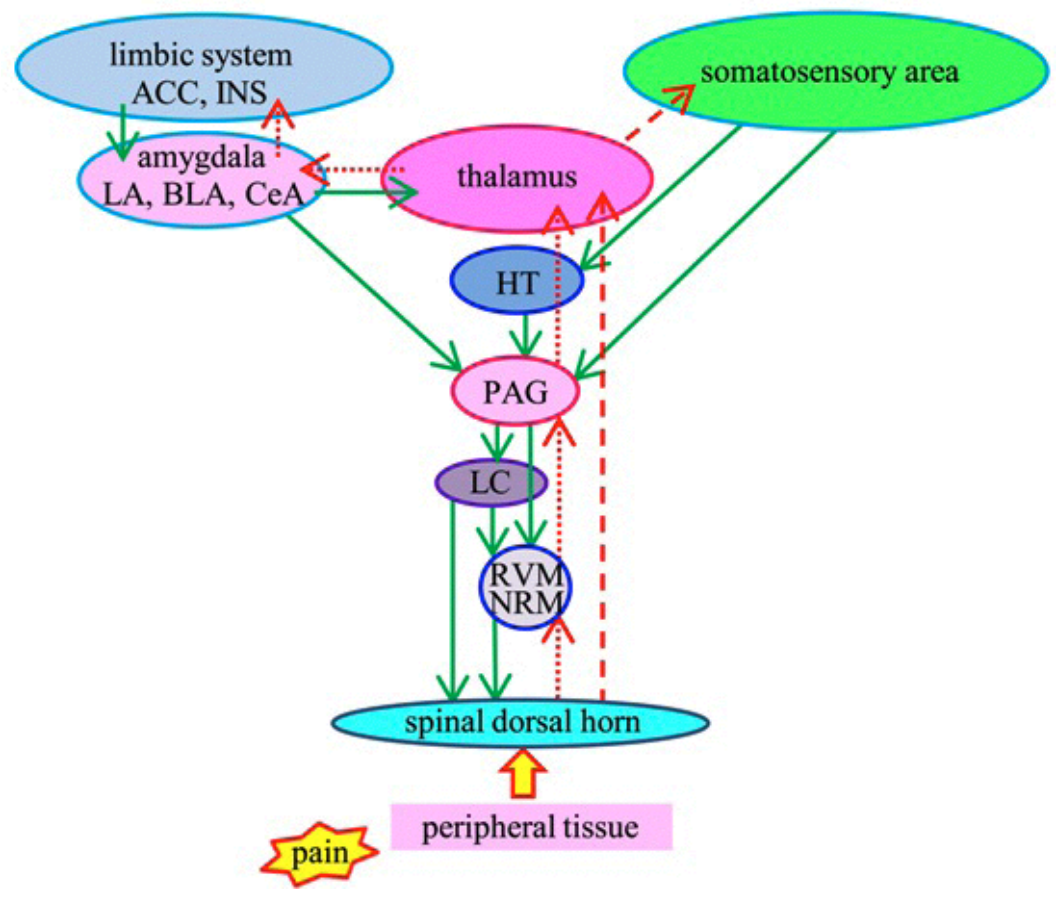

Fig. (10). Schematic representation of pain modulatory circuitry.

Upward arrows represent lateral (red broken lines) and medial (red dotted lines) ascending nociceptive pathways. Lateral pathway is related to discrimination of pain perception and medial is related to emotion. Downward arrows (green solid lines) represent descending antinociceptive pathway. ACC: anterior cingulate cortex, INS: insular cortex, LA: lateral nucleus of the amygdala, BLA: basolateral nucleus of the amygdala, CeA: central nucleus of the amygdala, HT: hypothalamus, PAG: periaqueductal gray, LC: locus ceruleus, RVM: rostral ventromedial medulla, NRM: nucleus raphe magnus.

neurotransmitters and neuronal excitability. This results in inhibition of the ascending excitatory nociceptive transmissions and activation of the descending inhibitory system [13, $14,24]$. MOR activation of the descending pain-control circuits depends on an opioid related to GABAergic neurotransmission in the PAG $[25,26]$. Human imaging studies with $\left[{ }^{11} \mathrm{C}\right]$-carfentanil revealed that placebo analgesia was related to activation of MORs in the rostral ACC, pregenual cingulate cortex, dorsolateral prefrontal cortex, and the anterior INS [27]. Thus, endogenous opioids in the ACC are suggested to be involved in the antinociception. However, in the present study, only a few opioid peptides were observed in the ACC when electrical stimulation was applied to the $\mathrm{CeA}$ or noxious stimulation was applied to the peripheral tissue (not shown). These results may suggest that endogenous opioids in the ACC do not play a major functional role in the inhibition of neural discharge in the ACC. A previous study suggested that BLA-prefrontal cortex pathways inhibit prefrontal cortex nociceptive cell activities [10]. The pathway modified by the dopamine system may assign regulatory function.

The amount of $\beta$-endorphin in the PAG was more increased by noxious stimulation than with the other conditions (Fig. 4). The amount of $\beta$-endorphin in the MeA was increased by noxious stimulation as compared with control (Fig. 6). These results indicate that $\beta$-endorphin in the MeA expresses for invasive stimulation or the disfavor, and that in the PAG activates descending antinociceptive systems for noxious pain. $\beta$-endorphin may inhibit the transmission of nociceptive input at the level of the MeA and/or negative emotion from the amygdala to the ACC and INS, when nox- ious stimulation is applied to the peripheral tissue. The amount of dynorphin $\mathrm{A}$ in the MeA also showed similar tendency, but there was no significant difference. The amount of dynorphin $\mathrm{A}$ in the PAG was increased by electrical stimulation applied to the $\mathrm{CeA}$, and significantly higher than control or sham operated (Fig. 8). The results support that dynorphin $\mathrm{A}$ in the PAG activate descending painmodulatory systems. The amount of enkephalin in the MeA and PAG did not change significantly among each condition (not shown). $\beta$-endorphin immunopositive cell somata were observed in the arcuate nucleus, enkephalin and dynorphin A immunopositive cell somata were observed in the CeA and hypothalamus. It is thought that the some neurons may project to the MeA or PAG. However it is difficult to identify the cell body of neurons which produce opioids observed in the MeA or PAG.

In our study, the amount of dynorphin A was increased in the PAG by electrical stimulation applied to the CeA, and the amount of $\beta$-endorphin was increased in the MeA and PAG by noxious stimulation applied to the peripheral tissue. $\beta$-endorphin may express to prevent body as response to noxious pain and expression of dynorphin A in the PAG may relate with emotion. These results suggest that the opioids may depress the ascending nociceptive transmissions or activate descending antinociceptive system not only the endogenous opioidergic system but also noradrenergic system or serotonergic system, and result in antinociception (Fig. 10). That is, emotional stimulation at the amygdala increases dynorphin A in the PAG, which leads to relieve pain. In the clinical situation, patients with dental caries or infection in the oral cavity have acute or chronic pain and dental treat- 
ments frequently accompany with pain. If to stimulate into emotion is able to relieve pain, that helps some patients which are distressed by pain. For example, in the human, it is reported that listening to the music decreases pain perception of nociceptive stimulus [28, 29]. The effects results from endogenous opioids secreted by comfortable environmental conditions such as the hearing of pleasant music. Therefore to encourage pain relief in patients, the environmental modification would be a useful method in providing pain relief without drugs.

\section{CONCLUSION}

In the present study, the amount of dynorphin A was increased in the PAG by electrical stimulation applied to the $\mathrm{CeA}$, and the amount of $\beta$-endorphin was increased in the PAG and MeA by noxious stimulation applied to the peripheral tissue. In contrast, only a few endogenous opioids ( $\beta$ endorphin, enkephalin, dynorphin A) were observed in the ACC when noxious stimulation or electrical stimulation was applied. These results suggest that dynorphin A in the PAG induced by electrical stimulation into the CeA facilitate the descending antinociceptive system, and depress the nociceptive response in the ACC.

\section{CONFLICT OF INTEREST}

The authors confirm that this article content has no conflicts of interest.

\section{ACKNOWLEDGEMENT}

Declared none.

\section{REFERENCES}

[1] Ossipov MH, Dussor GO, Porreca F. Central modulation of pain. J Clin Invest 2010; 120(11): 3779-87.

[2] Phelps EA, LeDoux JE. Contributions of the amygdala to emotion processing: from animal models to human behavior. Neuron 2005; 48: $175-87$.

[3] Manning BH, Martin WJ, Meng ID. The rodent amygdala contributes to the production of cannabinoid-induced antinociception. Neuroscience 2003; 120: 1157-70.

[4] Li W, Neugebauer V. Differential roles of mGluR1 and mGluR5 in brief and prolonged nociceptive processing in central amygdala neurons. J Neurophysiol 2004; 91: 13-24.

[5] Ortiz JP, Heinricher MM, Selden NR. Noradrenergic agonist administration into the central nucleus of the amygdala increases the tail flick latency in lightly anesthetized rats. Neuroscience 2007; 148(3): 737-43.

[6] Kawarada K, Kamata K, Matsumoto N. Effect of electrical stimulation of the central amygdaloid nucleus on the nociceptive neuron of the cortex (SI) in the cat. Jpn J Physiol 1996; 46: 485-90.

[7] Oliveira MA, Prado WA. Antinociception induced by stimulating amygdaloid nuclei in rats: changes produced by systemically administered antagonists. Braz J Med Biol Res 1998; 31: 681-90.
[8] Mena NB, Mathur R, Nayar U. Amygdalar involvement in pain Indian J Physiol Pharmacol 1995; 39: 339-46.

[9] Onozawa K, Yagasaki Y, Izawa Y, Abe H, Kawakami Y. Amygdala-prefrontal pathways and the dopamine system affect nociceptive responses in the prefrontal cortex. BMC Neurosci 2011; 12: 115 .

[10] Zhang R, Tomida M, Katayama Y, Kawakami Y. Response durations encode nociceptive stimulus intensity in the rat medial prefrontal cortex. Neuroscience 2004; 125: 777-85.

[11] Schoell ED, Bingel U, Eippert F, et al. The effects of opioid receptor blockade on the neural processing of thermal stimuli. PLos One 2010; 5(8): e12344.

[12] Taketa Y, Niikura K, Kobayashi Y, et al. Direct evidence for the ongoing brain activation by enhanced dynorphinergic system in the spinal cord under inflammatory noxious stimuli. Anesthesiology 2010; 112: 418-31.

[13] Dickenson AH, Kieffer B. In: McMahon SB, Koltzenburg M, Eds. Wall and Melzack's Textbook of Pain. $5^{\text {th }}$ ed. Philadelphia: Churchill Livingstone 2006; pp. 427-42.

[14] Mansour A, Foc CA, Akil H, Watson SJ. Opioid-receptor mRNA expression in the rat CNS: anatomical and functional implications. Trends Neurosci 1995; 18(1): 22-9.

[15] Mansour A, Khachaturian H, Lewis ME, Akil H, Watson SJ. Anatomy of CNS opioid receptors. Trends Neurosci 1988; 11(7): 30814.

[16] Tempel A, Zukin RS. Neuroanatomical patterns of the $\mu, \delta, \kappa$ opioid receptors of rat brain as determined by quantitative in vitro autoradiography. Proc Natl Acad Sci USA 1987; 84: 4308-12.

[17] Kapitzke D, Vetter I, Cabot PJ. Endogenous opioid analgesia in peripheral tissue and the clinical implications for pain control. Ther Clin Risk Manag 2005; 1(4): 279-97.

[18] Eippert F, Bingel U, Schoell E, Yacubian J, Büchel C. Blockade of endogenous opioid neurotransmission enhances acquisition of conditioned fear in humans. J Neurosci 2008; 28(21): 5465-72.

[19] Manning BH. A lateralized deficit in morphine antinociception after unilateral inactivation of the central amygdala. J Neurosci 1998; 18: 9453-70.

[20] Millan MJ. Descending control of pain. Prog Neurobiol 2002; 66(6): 355-474.

[21] Sah P, Faber ES, Lopez De Armentia M, Power J. The amygdaloid complex: anatomy and physiology. Physiol Rev 2003; 83: 803-34.

[22] Chieng BC, Christie MJ, Osborne PB. Characterization of neurons in the rat central nucleus of the amygdala: cellular physiology, morphology, and opioid sensitivity. J Comp Neurol 2006; 497: 910-27.

[23] Manning BH, Mayer DJ. The central nucleus of the amygdala contributes to the production of morphine antinociception in the formalin test. Pain 1995; 63(2):141-52.

[24] Sharma SK, Klee WA, Nirenberg M. Opiate-dependent modulation of adenylate cyclase. Proc Natl Acad Sci USA 1977; 74(8): 3365-9.

[25] Fields, H. State-dependent opioid control of pain. Nat Rev Neurosci 2004; 5: 565-75.

[26] McNally GP, Cole S. Opioid receptors in the midbrain periaqueductal gray regulate prediction error during pavlovian fear conditioning. Behav Neurosci 2006; 120: 313-23.

[27] Zubieta JK, Bueller JA, Jackson LR, et al. Placebo effects mediated by endogenous opioid activity on mu-opioid receptors. J Neurosci 2005; 25(34): 7754-62.

[28] Bradshaw DH, Chapman CR, Jacobson RC, Donaldson GW. Effects of music engagement on responses to painful stimulation. Clin J Pain 2012; 28(5): 418-27.

[29] Roy M, Lebuis A, Hugueville L, Peretz I, Rainville P. Spinal modulation of nociception by music. Eur J Pain 2012; 16: 870-7.

Received: December 17, 2012

(C) Nakamura et al.; Licensee Bentham Open.

This is an open access article licensed under the terms of the Creative Commons Attribution Non-Commercial License (http://creativecommons.org/licenses/by-nc/3.0/) which permits unrestricted, non-commercial use, distribution and reproduction in any medium, provided the work is properly cited. 